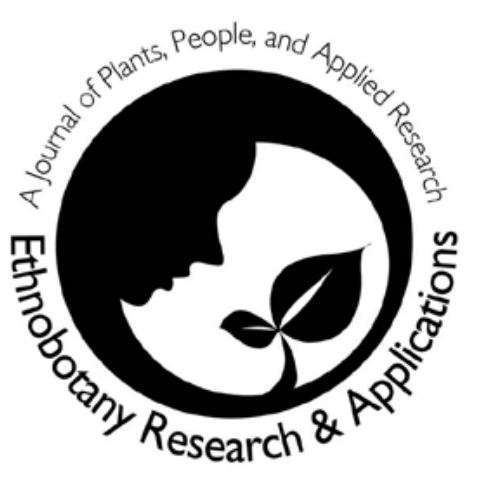

\title{
Bamboo Resources in Ethiopia: Their value chain and contribution to livelihoods
}

\author{
Zenebe Mekonnen, Adefires Worku, Temesgen Yohannes, \\ Mehari Alebachew, Demel Teketay, and Habtemariam Kassa
}

\section{Research}

\begin{abstract}
Ethiopia has an estimated one million hectares of natural bamboo forest, the largest in the African continent. Despite the versatile resource base and advanced bamboo utilization at a global scale, its great potential to enhance socio-economic and ecological development remains unrealized in Ethiopia. More importantly, recent observations in the country showed massive bamboo flowering followed by a death that urges management interventions. The objective of this study was to examine the socio-economic contribution of bamboo resources and typify their marketing value chain across major bamboo-growing and -marketing regions in Ethiopia, in order to promote its sustainable management. Structured questionnaires were administered to a total of 345 households to inspect the relative contribution of bamboo income to household economy. Participatory rural appraisal, key informant interviews, group discussions, market assessment, and field observations were made to understand the bamboo marketing system, actors involved, price trends, and factors affecting the bamboo value chain. Results show that crop and livestock production, forest management, and off-farm activities are major sources of income for respondent households. Fifty-three percent of the respondents reported bamboo income. Though it significantly varies across the study localities ( $p<0.005)$, bamboo income contributed up to $11 \%$ of the annual cash income of the households, the lowest (3.4\%) at Masha and the largest $(38 \%)$ at Banja and Bahir Dar Zuria Districts. Positive and significant correlation was observed among cash incomes from bamboo, crop, petty trade, and other Non-Timber Forest Products (NTFPs). Producer farmers, village level traders, town and city wholesalers, small- and medium-scale bamboo processing and marketing firms, and town and city consumers are identified as major actors in the bamboo value chain. Fifty-five percent of the respondents indicated presence of poor horizontal and vertical
\end{abstract}

linkage among actors. Access to market is difficult for a majority $(88 \%)$ of the producers, and hence they sell bamboo culms and other product forms locally, mainly in roadside markets. Despite the inefficient value chains, $85 \%$ of the respondents indicated an increasing trend of demand for bamboo products. Market assessment for bamboo culms showed a price elasticity of demand, which is the change in quantity divided by change in price, up to 1.21 in 2008/2009 and 1.47 in 2009/2010. Nevertheless, bamboo utilization in Ethiopia is basically rudimentary, and bamboo product import exceeds export, in contrast to the resource base of the country. It is also noteworthy that the resource base is declining alarmingly in spite of the little interventions in place. An important policy and development lesson include enhancing further research

\section{Correspondence}

Zenebe Mekonnen, Wondo Genet Agricultural Research Center, P.O. Box 198, Shashemene, ETHIOPIA. zenebemg2014@gmail.com

Adefires Worku, Dresden Technical University, Institute of International Forestry and Forest Products, Postfach 1117, 01735, Dresden, GERMANY.

Adefires Worku, Temesgen Yohannes, Forestry Research Center, P.O. Box 30708, Addis Ababa, ETHIOPIA.

Mehari Alebachew, Holeta Agricultural Research Center, Holeta, ETHIOPIA.

Demel Teketay, Botswana College of Agriculture, Department of Crop Science and Production, Private Bag 0027, Gaborone, BOTSWANA. dteketay@bca.bw, dteketay@yahoo.com

Habtemariam Kassa, Center for International Forestry Research Ethiopia Office, P.O. Box 5689, Addis Ababa, ETHIOPIA.

Ethnobotany Research \& Applications 12:511-524 (2014)

Published: 23 November 2014 
for technology innovation, upgrading and integrating the bamboo value chain, and promoting sustainable management of the resource base.

\section{Introduction}

Bamboo is becoming increasingly important in the world since: (i) it is a superior wood substitute; (ii) it is cheap, efficient, and fast growing; (iii) it has high potential for environmental protection; (iv) it has wide ecological adaptation; and (v) the state of forest is shrinking globally (Carr \& Hartl 2008, Kant 1996, Kibwage et al. 2008, Maoyi \& Bay 2004, Marshall et al. 2006, Nugroho \& Naoto 2001, Ogunjinmi et al. 2009, Rana et al. 2010). Under regular management practices including stand and soil management and yearly harvesting regimes, Yiping et al. (2010) found that bamboo forests are likely to sequester carbon at a similar level to fast-growing trees and, hence, significantly contribute to the efforts being made to mitigate climate change.

According to Zhaohua (2001), over 1500 distinct uses of bamboo have been recorded around the world, and the number is growing rapidly with new development and innovation initiatives. Different bamboo products that are excellent substitutes for timber-produced materials have been innovated in, mainly, China, India, and western countries (Maoyi \& Bay 2004). For example, bamboo floorboards, fabricated panels, handicrafts, curtains, modern ceilings, bio-energy, charcoal, paper, clothes, medicine, edible bamboo shoots, bamboo beer, bamboo soft drinks, etc. are important bamboo products in China (Bay 2004, Zhaohua 2001). The eco-tourism value of bamboo is also increasing during the past few decades (Lee \& Liu 2003).

ITTO (2002) estimated that over 2 billion people in the world depend on bamboo every day. Globally, one billion people live in bamboo houses, and bamboo housing in Costa Rica, other Latin American countries, and Ethiopia is a good example. According to INBAR (2010), an economy of 2.5 billion people comes from bamboo-related activities. Global annual trade earns 5-7 billion USD from bamboo, compared with the 8 billion USD return from tropical timber trade (ITTO 2002). In addition to its contribution to the national economy, development of a bamboo sub-sector in China improved income of local farmers significantly. According to Zhaohua and Yang (2004), for instance, the average bamboo income per household per year in Anji county of Hangzou province was 45\% in 2002.

Ethiopia is one of the few countries in the world endowed with a vast bamboo resource base (Embaye 2000, Kelbessa et al. 2000, Yemishaw et al. 2009). The country has an estimated one million hectares of natural bamboo forest, $7 \%$ of the world total and $67 \%$ of the African total (Embaye et al. 2003, FAO 2006, Wang 2006). The two indig- enous bamboo species in Ethiopia are the African alpine bamboo, Yushania alpina (K.Schum.) W.C.Lin (a monopodial/leptomorphic rhizome bamboo), and a monotypic genus of lowland bamboo, Oxytenanthera abyssinica (A. Rich.) Munro (a sympodial/pachymorphic rhizome bamboo) (Embaye 2003, Hedberg \& Edwards 1995, Ohrnberger 1999). Although representative case studies are still rare, Adnew and Statz (2007) indicated that in Ethiopia, a great number of people are engaged in bamboo management to support their livelihoods. It was estimated that over 1.2 billion USD can be generated every year if the country's bamboo resource base is properly utilized (INBAR 2010). In their study on the role of bamboo for construction materials, Kibwage and Misreave (2011) reported that, bamboo accounted for $2-3 \%$ at the national level and more than $50 \%$ in rural areas of Southern Nation, Nationalities and People (SNNP) and Benshangul Gumuz National Regional States in Ethiopia.

However, unlike other countries, the development and utilization of bamboo in Ethiopia is fundamentally rudimentary, and its socio-economic and ecological potentials are not yet realized (Adnew \& Statz 2007). Despite the recent sporadic initiatives to develop and use bamboo, it has received little emphasis and not been well-integrated into the overall development planning. Rather, the currently alarming large scale deforestation of bamboo-growing areas coupled with the historical mass flowering and death of the species are resulting in loss of the unique resource before its economic, social, and environmental advantages are understood and appreciated (Gebremariam et al. 2009, Sertse et al. 2011). The customary and current bamboo use is far below its potential due to lack of knowledge and skills on bamboo silviculture and poor establishment and management of bamboo stands (Embaye et al. 2003, Haile 2008, Kelemwork 2008). The existing underdeveloped value chain of bamboo products and scarcity of case studies describing the socio-economic importance of bamboo resources at local and national economic scales are contributing to low interest in integrating and sustainably developing bamboo resources. Currently policy groups have given little attention to bamboo resources, hence, the rampant mass conversion of bamboo landscapes into commercial farm lands and re-settlement that has been threatening the existence of the resource base (Kibwage \& Misreave 2011, Sertse et al. 2011).

In Ethiopia, demand for industrial wood is $400,000 \mathrm{~m}^{3}$ $\mathrm{yr}^{-1}$ of which sawn wood accounts for $85 \%$ (Kelemwork 2008). Annual incremental yield from industrial plantations available as saw logs is estimated between 150,000 to $200,000 \mathrm{~m}^{3} \mathrm{yr}^{-1}$, and demand is in deficit of $200,000 \mathrm{~m}^{3} \mathrm{yr}^{-1}$ (FAO 2003). Currently, there is an acute shortage of forest products annually, with an expected increase of demand for lumber and wood-based products in the future (Gebremariam et al. 2009). Since the past few years, such a gap has triggered bamboo utilization and is becoming the major substitute of wood for rural and urban house construc- 


\section{Mekonnen et al. - Bamboo Resources in Ethiopia: Their value chain and contribution to livelihoods}

tion in Ethiopia (Alito 2005, Bewketu 2009, Gebremariam et al. 2009, INBAR 2010, Kibwage \& Misreave 2011). During the same period, there is a growing private investment in the bamboo-based businesses in the country. Sound development of bamboo resources and businesses, however, requires a good understanding of its contribution to: (i) local, regional, and national economies, (ii) production and marketing systems, and (iii) factors affecting decisions to engage, develop, and benefit from the bamboo resources across the major bamboo-growing regions (Adnew \& Statz 2007, Andargatchew 2008). Such understanding could facilitate improved utilization and sustainable management of the ever-declining bamboo forests and, thereby, enhance the penetration of small-holder producers into the lucrative markets through increased market information, market access, value adding, forging of partnerships, and proportional share of prices for bamboo products (Kelbessa et al. 2000).

To provide scientific information to some of the abovementioned gaps related to sustainable bamboo resources development in Ethiopia, we carried out a study aiming at: (i) describing current strategies in bamboo production to the marketing chain, stakeholders involved in the chain, and their respective roles and benefits; (ii) quantifying the value added as products move along the marketing chains; (iii) determining the relative contribution of bamboo income to household annual cash income; and (v) assessing the existing formal and informal institutional arrangements facilitating and/or hindering development, production, and marketing of bamboo and its products within the major bamboo-growing regions in Ethiopia.

\section{Materials and Methods}

\section{Selection and description of the study sites}

Natural bamboo forests grow in various regions in Ethiopia. Yushania alpina (highland bamboo) grows in the northwestern, western, southern, and central part of the country, whereas
Oxytenanthera abyssinica (lowland bamboo) is widely distributed in western and northwestern lowlands of the country (Embaye 2000). To undertake the study, we purposively selected four National Regional States based on their bamboo resources potential. A reconnaissance survey was made to identify and map major bamboo-growing hotspots and pockets within each region. A total of eight Districts-Banja and Bahir Dar Zuria from Amhara National Regional State (ANRS); Tikur Enchini from Oromia National Regional State (ONRS); Chencha, Hula, and Masha from Southern Nations, Nationalities and Peoples National Regional State (SNNPNRS); and Bambasi and Asosa from Benshangul-Gumuz National Regional State (B-GNRS) (Figure 1)—were systematically selected using accessibility, resource endowment, existence of government and NGO initiatives in the bamboo resources, history of bamboo product marketing, and households' participation in bamboo management and use as criteria. The proportion of study sites were based on the area coverage of bamboo resources in the respective region. In addition, we purposively selected three major cities: Bahir Dar from ANRS, Hawassa from SNNPNRS, and Addis Ababa, capital city of the Federal Government of Ethiopia, to represent major bamboo processing and marketing areas in the country (Adnew \& Statz 2007).

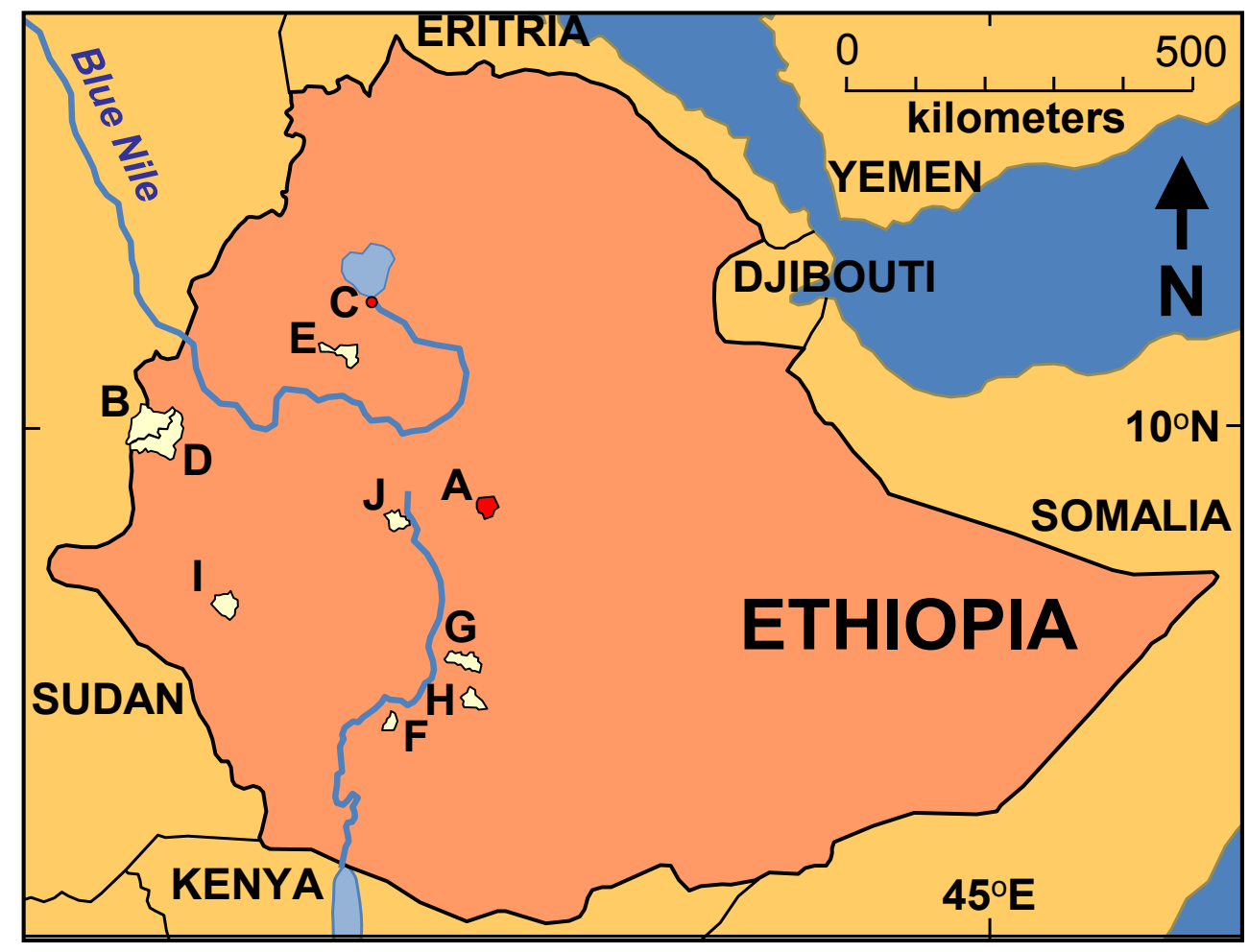

Figure 1. Study localities in bamboo-growing and -processing regions of Ethiopia. Addis Abeda (A), Asosa (B), Bahir Dar (C), Bambasi (D), Banja (E), Chencha (F) Hawasa (G), Hula (H), Masha (I), Tikur Enchini (J) 


\section{Respondent sampling and data collection}

Rapid rural appraisal (RRA) techniques were used to understand the overall socio-economic situation of the selected study localities, households, and communities. Based on such background information, a total of 345 households (30 from Banja, 27 from Bahir Dar Zuria, 49 from Tikur Enchini, 28 from Hula, 60 from Chencha, 51 from Masha, 50 from Asosa, and 50 from Bambasi) were randomly selected for questionnaire surveys using random number and resident lists, where the head of the household was interviewed (Creswell 2009, Yin 2009). The survey focused on sources of household income, relative dependence on bamboo income, actors involved in the bamboo production-to-consumption value chain, bamboo marketing system and pricing, and factors affecting household engagement in and benefits from the bamboo development and production system. Various researchers (e.g. Campbell et al. 2002, Mamo et al. 2007, Tesfaye et al. 2011, Vedeld et al. 2007) followed more or less similar procedures to the above-mentioned indicators to understand the relative contribution of forest resources to livelihoods in rural areas in different parts of the world.

Intensive group discussions, key informant interviews, and field level observations were made at local, District, zonal, and regional levels involving farmer producers, small- and medium- scale bamboo processing firm mangers, and experts from government and NGOs to better understand the: (i) structure of the production and marketing chain of the bamboo resources across different regions, (ii) actors involved in the bamboo value chain, and (iii) value added in the bamboo businesses integration. Information on local price and demand of bamboo products was collected through market assessment where different actors, including producers and buyers (retailers, wholesalers, and consumers) were interviewed to triangulate the precision of information (Campbell et al. 2002). We also followed the products across different segments of markets to better observe pricing and modes of negotiation and characterize actors in the value chain. Nine bamboo-based small firm owners, three bamboo yard owners, one bamboo-based medium-scale industry owner, and one manager of a bamboo furniture-making enterprise were identified using snowball techniques and interviewed on issues related to access to raw materials, processing technology, markets, and opportunities and challenges existing in bamboo businesses in general and at the enterprise/firm level in particular. In addition, statistical data on bamboo export and domestic markets were collected from Ethiopian Revenues and Customs Authority (ERCA) and Ethiopian Tourist Trade Enterprise (ETTE).

\section{Data analyses}

Descriptive statistics and ANOVA were used to determine the relative contribution of bamboo income to the household economy and major household level socio-econom- ic factors that influence engagement in and benefit from bamboo management (Tesfaye et al. 2011). Qualitative data were summarized by condensing the information and were used to elaborate the results from quantitative analysis (Yin 2009).

\section{Results}

\section{Socio-economic characteristics of respondents and factors influencing bamboo management}

A majority of the sample respondents were male-headed households $(86 \%)$. The average family size of the respondents was 6 persons, ranging between 3 and 12. Respondents' age classification shows that youth between 20 and 30 years and older than 50 years dominate. Interestingly, a majority of the households within these two groups engage in bamboo management, followed by the middle age groups, implying participation in bamboo management is mainly the job of youth and the older generation. This could be attributed to the fact that the youth engage more in cash income activities, while the older generation might prefer to engage in less labor-intensive farming activities, such as bamboo planting or collection of the freely available bamboo products. Based on the criteria developed in a participatory manner using household's land size, number of livestock, house type, and other household assets, respondents were categorized as poor, medium, and rich, where poor households represented $46 \%$ and only $12 \%$ were categorized as rich. The majority of respondents $(78 \%)$ were illiterate with only $12 \%$ having completed primary school and $10 \%$ secondary school (Table 1 ).

According to the group discussions and key informant interviews, involvement of households in bamboo-based activities was affected by household level socio-economic characteristics, such as gender, age, wealth status, and associated perceptions. In areas where bamboo culms come from natural forests, which are often located far from resident areas, female-headed households showed reluctance to engage in bamboo business compared to maleheaded households. However, once bamboo culms reach resident areas, engagement of female-headed household increases. Young and middle age-headed households tend to diversify income and, hence, participate more in cash-generating activities, such as bamboo production and marketing. A considerable number of respondents $(25 \%)$ had the opinion that products made of bamboo, for instance, are utilities of "poor people," suggesting that opinions of households also have their effects on the decision of households to engage in bamboo-based livelihood activities. In addition to household socio-economic characteristics, other factors, such as market demand for bamboo products, distance from market and raw material source, peak agricultural time, and consumer characteristics affect decision of households to engage in bamboorelated businesses. 


\section{Mekonnen et al. - Bamboo Resources in Ethiopia: Their value chain and contribution to livelihoods}

Table 1. Demographic characteristics of households $(N=345)$ involved in bamboo activities in bamboo-growing regions in Ethiopia.

\begin{tabular}{|c|c|c|c|c|c|c|c|c|}
\hline \multirow[b]{3}{*}{ Age } & \multicolumn{8}{|c|}{ Household head involvement in bamboo activities } \\
\hline & \multicolumn{4}{|c|}{ By wealth status } & \multicolumn{4}{|c|}{ By gender } \\
\hline & Poor & Medium & Rich & Total & Men & Women & Both & Total \\
\hline \multirow[t]{2}{*}{$\leq 20$} & 4 & 3 & 0 & 7 & 3 & 4 & 0 & 7 \\
\hline & $1.2 \%$ & $0.9 \%$ & $0 \%$ & $2.0 \%$ & $0.9 \%$ & $1.2 \%$ & $0 \%$ & $2.0 \%$ \\
\hline \multirow[t]{2}{*}{$21-30$} & 51 & 32 & 7 & 90 & 68 & 10 & 12 & 90 \\
\hline & $14.8 \%$ & $9.3 \%$ & $2.0 \%$ & $26.1 \%$ & $19.7 \%$ & $2.9 \%$ & $3.5 \%$ & $26.1 \%$ \\
\hline \multirow[t]{2}{*}{$31-40$} & 37 & 30 & 13 & 80 & 63 & 11 & 6 & 80 \\
\hline & $10.7 \%$ & $8.7 \%$ & $3.8 \%$ & $23.2 \%$ & $18.3 \%$ & $3.2 \%$ & $1.7 \%$ & $23.2 \%$ \\
\hline \multirow[t]{2}{*}{$41-50$} & 30 & 32 & 13 & 75 & 52 & 14 & 9 & 75 \\
\hline & $8.7 \%$ & $9.3 \%$ & $3.8 \%$ & $21.7 \%$ & $15.1 \%$ & $4.1 \%$ & $2.6 \%$ & $21.7 \%$ \\
\hline \multirow[t]{2}{*}{$>50$} & 38 & 45 & 10 & 93 & 69 & 15 & 9 & 93 \\
\hline & $11.0 \%$ & $13.0 \%$ & $2.9 \%$ & $27.0 \%$ & $20.0 \%$ & $4.3 \%$ & $2.6 \%$ & $27.0 \%$ \\
\hline \multirow[t]{2}{*}{ Total } & 160 & 142 & 43 & 345 & 255 & 54 & 36 & 345 \\
\hline & $46.4 \%$ & $41.2 \%$ & $12.5 \%$ & $100 \%$ & $73.9 \%$ & $15.7 \%$ & $10.4 \%$ & $100 \%$ \\
\hline
\end{tabular}

\section{Relative contribution of bamboo resources to household income}

Except at a few study areas, crop and livestock production were the major income sources of the households followed by income from forest products (mainly fuel wood, bamboo, and honey) and off-farm activities (petty trade and employment). For instance, at Banja and Bahir Dar Zuria Districts, bamboo and petty trade, respectively, ranked second to crops in terms of cash income provision. Although it varied between study sites and among respon-

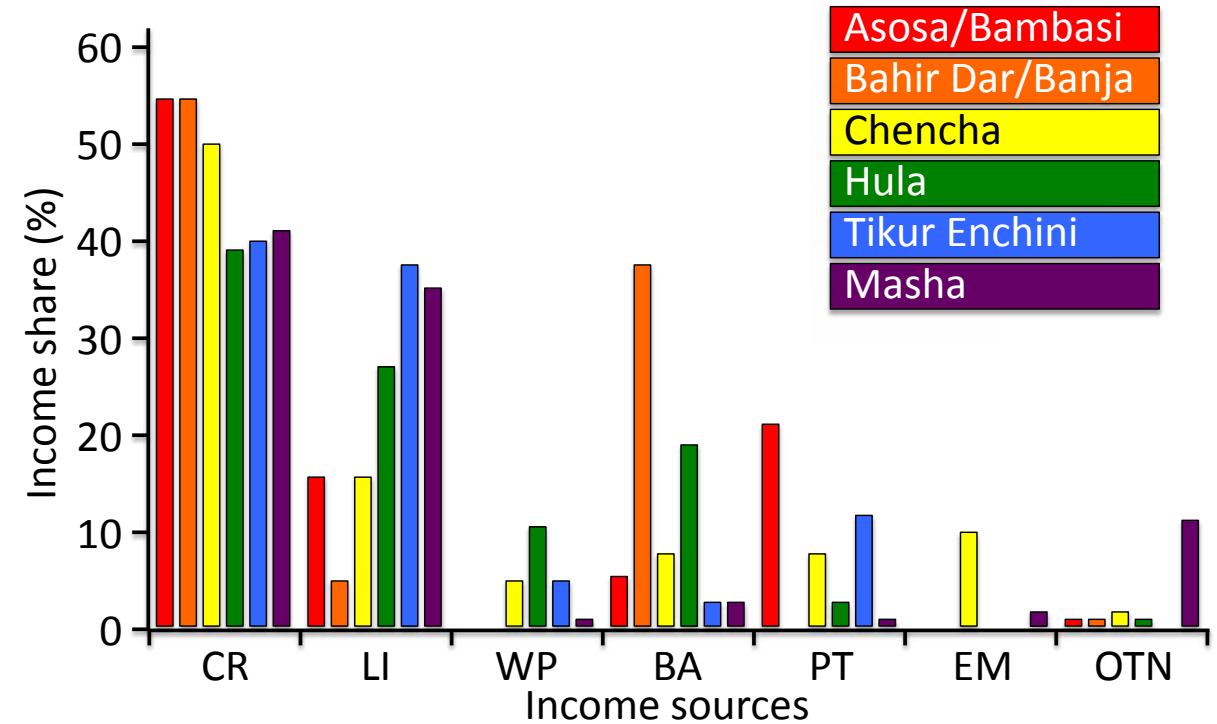

Figure 2. Sources of cash income of households and their share at six different bamboogrowing sites in Ethiopia. Income sources: crops (CR); livestock (LI); wood products (WP); bamboo (BA); petty trade (PT); employment (EM); other NTFPs excluding bamboo (OTN). dents, a large number of households (53\%) reported importance of bamboo cash income. The average annual relative contribution of bamboo to the household's cash income was $11 \%$, ranging between 4 and $38 \%$. At Banja and Hula Districts, bamboo contributed up to $38 \%$ and $18 \%$ of the household's annual cash income, respectively. In contrast, despite the huge natural bamboo resource base in Masha area (SNNPNRS) and in Asosa (B-GNRS), its contribution was very small (Figure 2 ). Analysis of variance (ANOVA) also showed a significant difference $(p<$ 0.005 ) of bamboo cash income among the study locali-

Asosa/Bambasi ties. Twenty-eight percent of the respondents rated the contribution of bamboo to the rural economy as very high, while $44 \%$, 23\%, and $5 \%$ rated it as high, medium, and low, respectively. On the other hand, the profitability of bamboo businesses was rated as high by $31 \%$ of the respondents while $42 \%$ and $26 \%$ rated it as medium and low, respectively. The bivariate analysis shows a positive and significant correlation of bamboo cash income with cash income from petty trade $(p<0.01)$ and other NTFPs $(p<0.01)$ at $\alpha=0.01$. It also positively and significantly correlated with crop cash income $(p<$ 0.025 ) at $\alpha=0.05$. Bamboo 
cash income showed minimal correlation to livestock production.

Efforts were made to identify both traditional and innovative types of bamboo uses across the study areas. Though traditional in nature, various local bamboo uses were identified. The three major uses included use of bamboo as construction material, for making furniture, and as livestock fodder (Table 2). A considerable number of respondents mentioned bamboo as a source of food. However, bamboo is the least preferred species for making charcoal at most of the study localities. Among all the study localities, bamboo charcoaling is reported only in Hula (Hagereselam area), while bamboo as food was reported only in Masha and Asosa areas.

Table 2. Major bamboo uses across bamboo-growing regions in Ethiopia.

\begin{tabular}{|l|c|c|}
\hline \multirow{2}{*}{$\begin{array}{l}\text { Identified local bamboo } \\
\text { uses }\end{array}$} & \multicolumn{2}{|c|}{$\begin{array}{c}\text { Proportion (\% of } \\
\text { respondents) (N = 345) }\end{array}$} \\
\cline { 2 - 3 } & Yes & No \\
\hline Food & 39.1 & 60.9 \\
\hline Charcoal & 5.2 & 94.8 \\
\hline $\begin{array}{l}\text { Construction } \\
\text { (house + fence) }\end{array}$ & 100 & 0 \\
\hline Fodder & 79.3 & 20.7 \\
\hline Furniture & 88.6 & 11.4 \\
\hline
\end{tabular}

\section{Marketing of bamboo products}

Results from the survey and key informant interviews showed an inefficient bamboo marketing chain at all the studied areas. For instance, $28 \%, 55 \%$, and $12 \%$ of respondents rated no linkage, poor linkage, and moderately good linkages, respectively, in the horizontal chain of bamboo marketing (expanding business at the same point within the supply chain in the same firm or other). Similarly, only $16 \%$ of respondents described the vertical chain (the acquisition of firms at different stages of production/ distribution within the same firm) as sustainable (i.e., continuous), while $55 \%$ and $29 \%$ rated it as intermittent (i.e., unsustainable and season-based/variable), respectively. The relationship between bamboo growers and traders was categorized as exploitative and fair by $69 \%$ and $26 \%$ of the respondents, respectively.

Table 3. Profitability analysis of bamboo yard markets in Addis Ababa, Ethiopia (August 2010).

\begin{tabular}{|l|l|l|l|l|l|}
\hline Bamboo yard & $\begin{array}{l}\text { Average annual } \\
\text { culm supply }\end{array}$ & Sourcing site & $\begin{array}{l}\text { Average annual } \\
\text { revenue }\end{array}$ & $\begin{array}{l}\text { Average } \\
\text { annual cost }\end{array}$ & $\begin{array}{l}\text { Average annual } \\
\text { net income }\end{array}$ \\
\hline Yard 1 & 20,000 & Gurage & $\$ 15,455$ & $\$ 9,062$ & $\$ 6,393$ \\
\hline Yard 2 & 1,000 & Injibara & $\$ 1,441$ & $\$ 1,095$ & $\$ 345$ \\
\hline Total & 21,000 & & $\$ 16,896$ & $\$ 10,157$ & $\$ 6,738$ \\
\hline
\end{tabular}

Nearly $88 \%$ of bamboo-growing respondents sell their bamboo products, including bamboo culms, at local and roadside markets, and $5 \%$ sell at regional markets; only $7 \%$ use bamboo for domestic consumption. The responses of households on the characteristics of consumers in the bamboo product markets revealed that about $33 \%$ and $34 \%$ of the consumers preferred furniture made of bamboo and timber, respectively. It is also worth noting that furniture made of bamboo was much less known by about $10 \%$ of the respondents. Market assessment at Hawasa showed that the price for different bamboo products was rewarding for those firms involved in bamboobased small-scale industries. For instance, a bed made of bamboo with a dimension of $2 \mathrm{~m} \times 1.5 \mathrm{~m}$ with a production cost of $\$ 54.00$ was sold at $\$ 137.00$, resulting in a net profit of $\$ 83.00$ in 2010. A similar assessment of randomly selected bamboo yards in Addis Ababa indicated that the annual return from the sale of raw bamboo and bamboo products was high and depended on the capital of the owner to bring sufficient raw material from the sourcing sites (Table 3).

\section{Bamboo production-to-consumption system}

Our survey of different firms and enterprises showed that the quality of bamboo products is not up to the desired specification and standards. Most bamboo products are traditional and used at local markets. However, some medium-scale enterprises [e.g., Adal Industrial Engineering Private Company Limited (AIEPCL)] have been recently established to produce charcoal briquettes, curtains, and sandal sticks. Discussions with enterprise owners revealed that the bamboo value chain does not conform to the three pillars of an effective value chain: increased system efficiency, improved quality, and development of differentiated products. According to the opinions of enterprise owners, production of good quality and differentiated products will: (i) minimize the increasing stern competition among them, (ii) enable producers, processors, and retailers to track their products through the value chain, and (3) deserve premiums for a consistently high quality product. In addition, they believe that if producers, processors, and traders work together, there will be opportunities to lower costs and increase efficiencies in the market. Consumer demand assessment, on the other hand, shows differentiated products that have high quality and are durable.

Processing and marketing of bamboo products in most study localities represents one of the very weak value 


\section{Mekonnen et al. - Bamboo Resources in Ethiopia: Their value chain and contribution to livelihoods}

Table 4. Bamboo value addition and coordination of actors along a market chain in Ethiopia.

\begin{tabular}{|l|l|c|c|}
\hline Actors & Products & Value added & Price \\
\hline $\boldsymbol{\nabla}$ Farmers & Raw bamboo & Nil / low & Low \\
\hline $\boldsymbol{\nabla}$ Semi-processors & Woven bamboo sheets & Medium & Medium \\
\hline $\boldsymbol{\nabla}$ Lumber processors & Bamboo lumber & High & High \\
\hline $\boldsymbol{\nabla}$ Furniture producers & Chairs made from bamboo lumber & Very high & Very high \\
\hline
\end{tabular}

chains, and there is a lack of application of technologies. Limited experience was observed during field observations to upgrade bamboo products in comparison with the well over 1500 product types globally. Existing examples of product upgrading at various study areas include diversifying from traditional bamboo use, such as for making grain store, baskets, chairs, and tables, to modern products, like curtains, sandal sticks, briquettes, and match sticks. According to city-based bamboo firms, the new line products are gaining very high value in some market niches. Concerning the functional upgrading, there are bamboo-based enterprises, such as Ethiopian Tourist Trade Enterprise (ETTE) and AIEPLC, which have taken new functions such as export marketing and the more lucrative roles within the value chain. Some new initiatives have been aimed at producing new marketable products, such as lumber and curtains, indicating the beginning of bamboo value chain upgrading (Table 4 ).

The value chain analysis revealed that there are three major channels/dimensions in the bamboo production-toconsumption chain at the study localities and in Ethiopia: (i) the vertical channel that shows the flow of raw bamboo from its production in a natural or cultivated system to the final consumer through various transactions and processes, (ii) the horizontal dimension where bamboo-based firms operating at a particular point in the market chain and the scale of activities and relationships among them, and (iii) the intensity, which relates to the amount of labor and capital that is used to carry out a particular function. Both price and intensity increased at each stage of vertical dimension and each firm level at the horizontal dimension. Market observations show that the vertical channel is characterized by raw bamboo transformation followed by marketing and the product reaching end consumers. In the horizontal dimension, producer farmers sell their bamboo culms to local traders, where the local traders sell it to town or city processors from where the products reach end consumers (Figure 3).

The bamboo value chain in Ethiopia is not targeted to the export market. Almost all bamboo products are produced traditionally and manually and used for the domestic market except some recent efforts to produce a few products by using advanced technology. The improved quality of the products associated with increased value addition



Figure 3. A framework of the bamboo production-to-marketing chain in Ethiopia. 
Table 5. Value addition to maximize profit from bamboo product sales in Ethiopia (October 2010). ${ }^{* *}=$ Value addition is high; * = values addition is low.

\begin{tabular}{|c|c|c|c|c|c|c|}
\hline \multirow[t]{3}{*}{ Products } & \multicolumn{6}{|c|}{ Average values (\$) } \\
\hline & \multicolumn{3}{|c|}{ Firm 1** } & \multicolumn{3}{|c|}{ Firm 2* } \\
\hline & $\begin{array}{r}\text { Production } \\
\text { cost }\end{array}$ & Selling price & Profit & $\begin{array}{r}\text { Production } \\
\text { cost }\end{array}$ & Selling price & Profit \\
\hline Chairs & 15.18 & 23.08 & 7.90 & 1.82 & 3.95 & 2.13 \\
\hline Tables & 7.29 & 15.49 & 8.20 & 1.21 & 4.25 & 3.04 \\
\hline Shelves & 7.90 & 16.40 & 8.50 & 4.25 & 5.77 & 1.52 \\
\hline Beds & 36.44 & 91.10 & 54.66 & 6.07 & 21.26 & 15.18 \\
\hline Partitions & 15.18 & 23.69 & 8.50 & - & - & - \\
\hline Sofas & - & - & - & 2.43 & 9.11 & 6.68 \\
\hline Stools & - & - & - & 0.91 & 3.64 & 2.73 \\
\hline Mats & - & - & - & 0.91 & 2.73 & 1.82 \\
\hline
\end{tabular}

helped producers, processors, and marketers maximize their profit (Table 5). The ETTE is one of the government institutions that produces bamboo furniture with its own specification and sells products to both national and international tourists in the country (Table 6)

\section{Demand and price trends of bamboo products}

During the survey, $85 \%$ of respondents mentioned an increasing trend of demand for bamboo products compared with the situation five years ago, while $9 \%$ and $6 \%$ mentioned a decreasing demand or no change, respectively. Respondents identified product quality, production and transport cost, characteristics of consumers, distance from resource base, and the added value to the product as major factors that determine the price of bamboo products in the market. Market surveys at different sites showed increasing price per bamboo culm and shortage of the supply (Figure 4). For instance, at Hagereselam village in Hula District of southern Ethiopia, the Price Elasticity of Demand (PED) for bamboo culms was 1.21 and 1.47 between 2008 and 2010 and between 2009 and 2010, respectively (Table 7 ).

In terms of the international marketing of bamboo products, the data from ERCA showed that the country is in

Table 6. Bamboo furniture specifications and selling price by the Ethiopian Tourist Trade Enterprise (October 2010). Area $=$ seat area; $\mathrm{FH}=$ front height; $\mathrm{BH}=$ back height.

\begin{tabular}{|c|c|c|c|c|c|}
\hline \multirow[t]{2}{*}{ Furniture } & \multicolumn{4}{|l|}{ Specification } & \multirow{2}{*}{$\begin{array}{l}\text { Selling } \\
\text { price (\$) }\end{array}$} \\
\hline & Area $(\mathrm{cm} \times \mathrm{cm})$ & $\mathrm{FH}(\mathrm{cm})$ & $\mathrm{BH}(\mathrm{cm})$ & Color & \\
\hline Chair & $43 \times 43$ & 46 & 100 & \multirow[t]{2}{*}{ Varnished/natural/brown } & 14.50 \\
\hline Chair with design & $47 \times 46$ & 46 & 86 & & 19.09 \\
\hline Chair with design & $45 \times 42$ & 46 & 94 & Varnished/natural/brown/green & 14.50 \\
\hline Sofa (single seater) & $55 \times 60$ & 42 & 76 & \multirow[t]{3}{*}{ Natural/brown } & 10.00 \\
\hline Sofa (double seater) & $69 \times 110$ & 42 & 76 & & 19.91 \\
\hline Garden chair & $54 \times 70$ & 33 & 67 & & 30.00 \\
\hline Coffee table & $80 \times 50$ & 50 & 50 & \multirow[t]{7}{*}{ Varnished/natural/brown } & 20.64 \\
\hline Dining table & $80 \times 80$ & 77 & 77 & & 42.27 \\
\hline Partition & $174 \times 5$ & 170 & 170 & & 52.36 \\
\hline Partition with leather & $150 \times 5$ & 185 & 185 & & 89.73 \\
\hline Bed & $135 \times 205$ & 45 & 100 & & 126.45 \\
\hline Bedside drawer & $45 \times 40$ & 58 & 78 & & 28.36 \\
\hline Drawer (5 parts) & $80 \times 50$ & 90 & 90 & & 63.18 \\
\hline Shelf & $75 \times 42$ & 170 & 170 & \multirow[t]{2}{*}{ Natural/brown } & 38.82 \\
\hline Shelf & $90 \times 42$ & 105 & 105 & & 22.36 \\
\hline
\end{tabular}



contribution to livelihoods

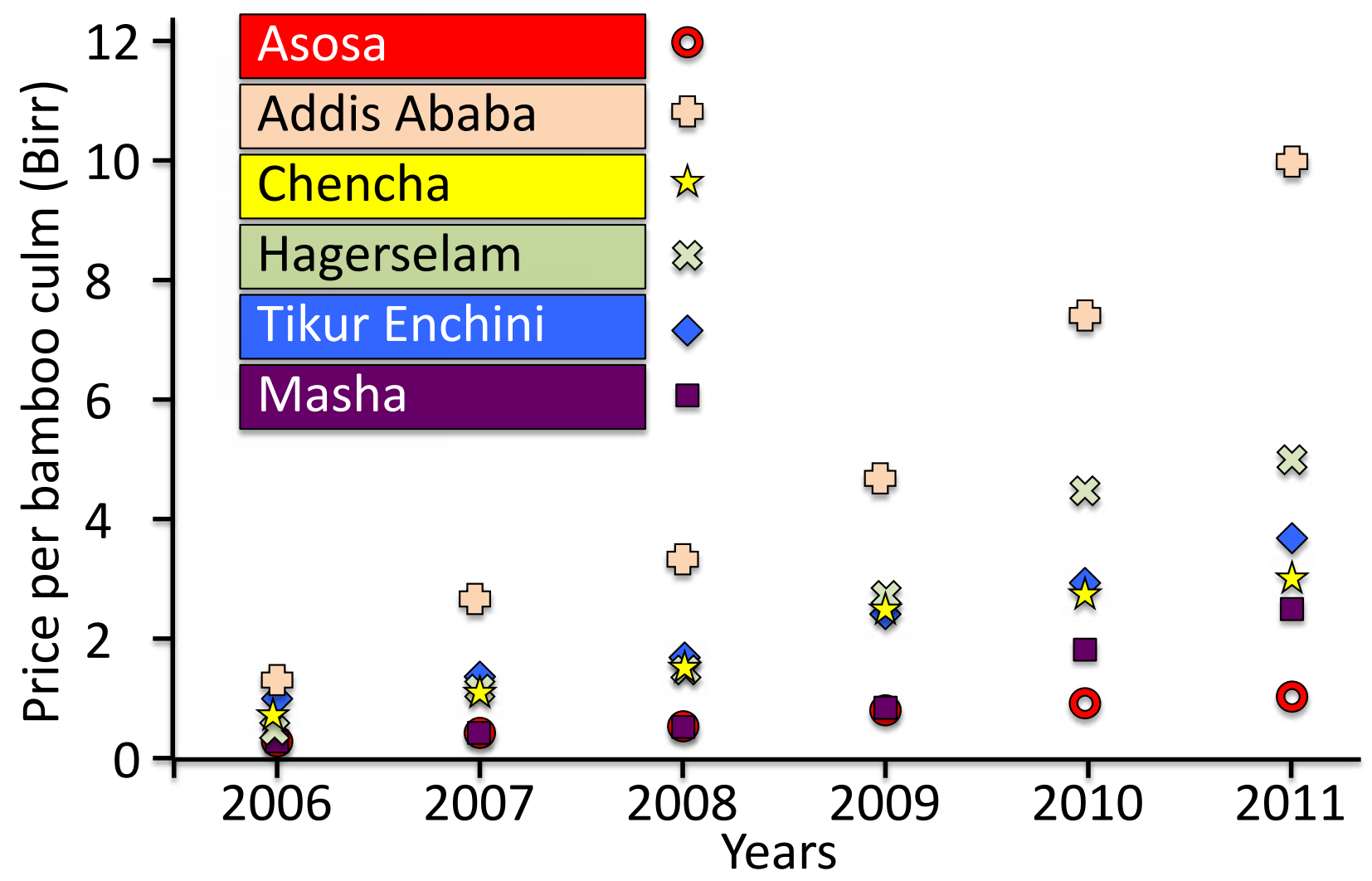

Figure 4. Price trend of bamboo culms at selected sites in Ethiopia.

Table 7. Bamboo culm Price Elasticity of Demand (PED) at Hula district, Hagereselam town, southern Ethiopia.

\begin{tabular}{|l|c|c|c|c|c|}
\hline Year & $\begin{array}{c}\text { Average price } \\
\text { (\$)/culm }\end{array}$ & $\begin{array}{c}\text { Percent change } \\
\text { in price }\end{array}$ & $\begin{array}{c}\text { Quantity of } \\
\text { culm demanded }\end{array}$ & $\begin{array}{c}\text { Percent change } \\
\text { in quantity }\end{array}$ & PED \\
\hline 2008 & 1.47 & 207 & 7 & -250 & -1.21 \\
\hline 2009 & 2.69 & 83 & 4 & -75 & -0.90 \\
\hline 2010 & 4.52 & 68 & 2 & -100 & -1.47 \\
\hline
\end{tabular}

a trade deficit as import is greater than export. The value of Cost of Insurance and Freight (CIF) paid and the corresponding value of tax obtained for the import market showed fluctuating trends (Figure 5).
Respondents also indentified several other factors constraining development of a pro-poor bamboo producers marketing system. These include lack of training, market information, and assistance to integrate producers with appropriate stakeholders and lack or fluctuating demand, mainly, at remote areas (Table 8).

Table 8. Factors affecting development of pro-poor bamboo producers marketing chain in rural Ethiopia.

\begin{tabular}{|l|c|}
\hline Marketing constraints in bamboo products & Proportion (\%) of respondents (N = 345) \\
\hline Lack of demand & 14.8 \\
\hline Competitors for similar products and market & 2.3 \\
\hline Lack of infrastructure & 17.7 \\
\hline Lack of market assistant program & 29.6 \\
\hline Shortage of raw material & 9.9 \\
\hline Low price & 0.6 \\
\hline Do not know since I use it for self consumption & 8.1 \\
\hline Two or more of the above mentioned factors & 17.1 \\
\hline
\end{tabular}




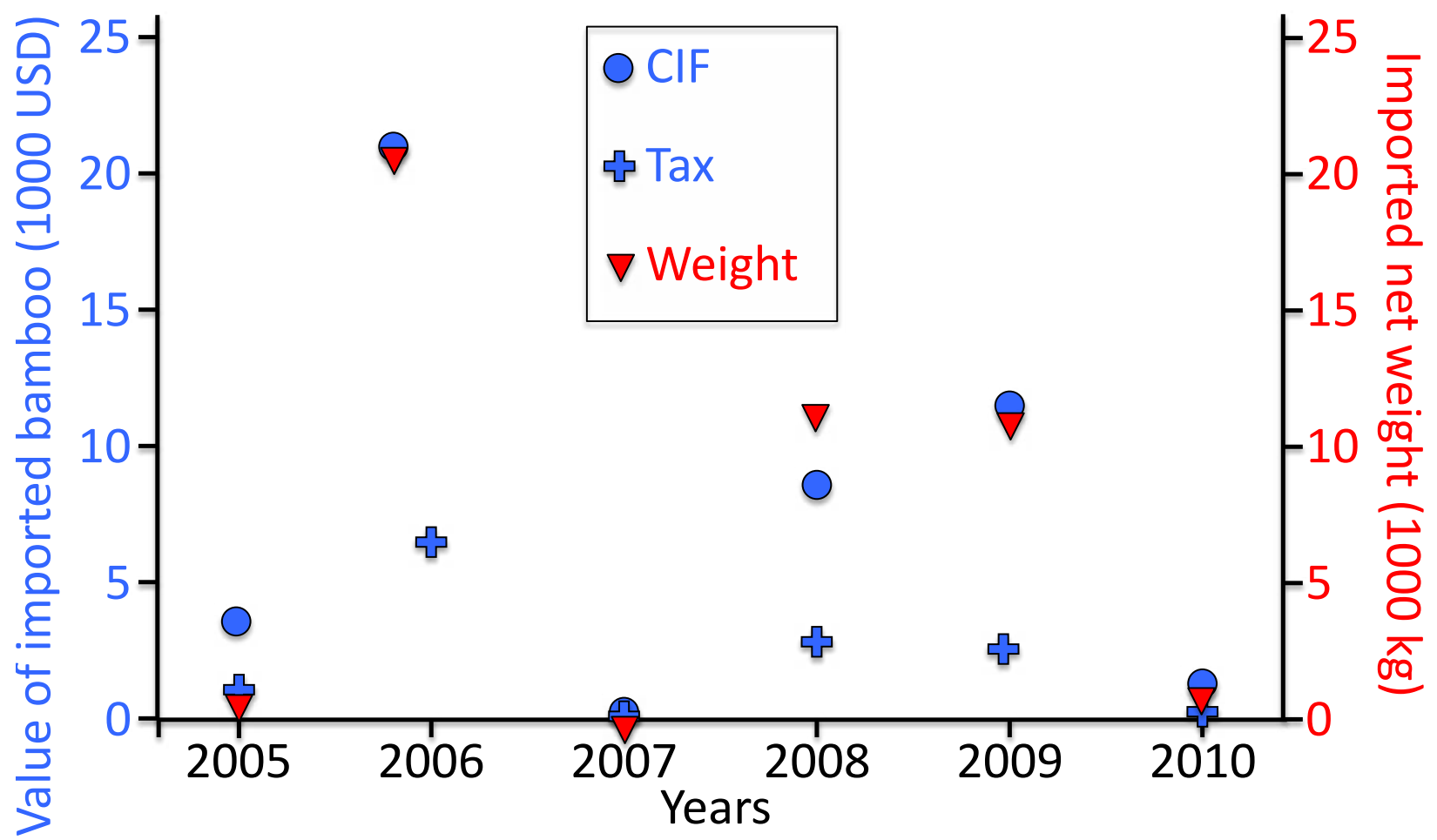

Figure 5. Value of Cost of Insurance and Freight (CIF) and tax trend in US Dollars and quantity of bamboo imported to the market in Ethiopia. Data from Ethiopian Revenues and Customs Authority and Ethiopian Tourist Trade Enterprise.

\section{Discussion and Recommendations}

There is an increasing consensus on the fact that forests, in addition to their multi-dimensional ecological importance, provide products that contribute to rural livelihood, poverty reduction, and income diversification, among others (Kamanga et al. 2009, Tesfaye et al. 2011, Worku et al. 2011). Rural households in developing countries consider diversifying income streams as a pathway to position themselves against agricultural production failure and natural disasters, which have the potential to propagate vulnerability (Babulo et al. 2008, Barrett et al. 2001, Ellis et al. 2003,). In addition to vulnerability reduction, multiple other factors, such as market opportunities, prompt households to engage in activities that might fetch income in a relatively short period of time and in a sustainable manner (Man \& Sadiya 2009, Vedeld et al. 2004, Vedeld et al. 2007). Similarly, the current study reveals that, though crop and livestock production were the main livelihood strategies that receive credible policy and extension support at the study areas, households tend to diversify into alternative livelihood activities. In general, crop and livestock production provide the major livelihood in most of the study localities and when pooled together constitute up to $71 \%$ of the annual household income. Households in Chencha, Banja/Bahir Dar Zuria, and Asosa/Bambais Districts derive a majority share of their income (> 50\%) from crop production, whereas households in Hula, Tikur
Enchini, and Masha Districts generate some $30 \%$ of their income from crop production. Livestock management is more important in Tikur Enchini (37.8\%), Masha (37\%), Hula $(26 \%)$, and relatively lesser contribution $(<20 \%)$ at the rest of the study localities. Crop- and livestock-dominated household economy was reported in various parts of Ethiopia. For instance, according to Mamo et al. (2007) crop and livestock provide $40 \%$ of the average total household income among sampled households at Dendi District, western Ethiopia. In their study at the northern part of Ethiopia, Babulo et al. (2008) also reported similar findings, where crop and livestock sectors together contributed to about $68 \%$ of the annual income of households.

In all the study localities, respondents mentioned presence of limited livelihood options, and, hence, they engaged in forest-based income activities where forests provide them with wood, fodder, food, medicine, cash income, and various socio-cultural values, which are crucial for day-to-day livelihood. Our study reveals that bamboo provides various subsistence benefits to households by way of furniture, farming tools, construction material, fuelwood, wood, and fodder, which, in this particular study, are not converted to monetary values. According to Kar \& Jacobson (2012) and Marshall et al. (2006), although the subsistence role of NTFPs is much higher in rural areas, they also serve as sources of cash income, where onethird of the surveyed households reported sale of various 


\section{Mekonnen et al. - Bamboo Resources in Ethiopia: Their value chain and 521 contribution to livelihoods}

NTFPs for cash. Similarly, the current study shows that bamboo provides cash income to a number of households that represent the lower, middle, and upper levels of the bamboo value chain. However, unlike various other areas in the world and in Ethiopia where forest products share a relatively significant proportion of household annual cash income, the economic contribution of bamboo resources in most of the current study areas can be defined as low. The average share of bamboo in the household's cash income is $11 \%$, ranging from $3.4 \%$ in Masha to $38 \%$ in Banja and Bahir Dar Zuria Districts pooled together. Bamboo also has a small contribution at Tikur Enchini (3.9\%), Asosa/Bambasi $(5.7 \%)$, and Chencha $(7 \%)$. Such a differential contribution of NTFPs across geographic regions was also reported by Vedeld et al. (2007) and Kamanga et al. (2009). In between is Hula District at Hagereselam area, where bamboo has a considerable contribution to the household's annual income (18\%), more than incomes from timber, other NTFPs, employment, and petty trade combined together.

The findings show presence of a significant difference in bamboo cash income dependence among the study households in different geographical areas in Ethiopia. For instance, despite the vast bamboo resource base at Masha and Asosa/Bambasi, the economic contribution of bamboo resources was minimal compared to other villages in Banja/Bahir Dar Zuria and Hula Districts. Villages in the latter Districts are becoming emerging markets for bamboo products, such as bamboo culms. According to DFID (1999) and Belcher et al. (2005), in general, engagement in a given livelihood diversification strategy varies from community to community as it is affected by various social and ecological factors including geographical location, which again, affects access to resource base, infrastructure, and market, among others. Those households that have access to markets may engage in more cash-generating activities than those in remote areas who might engage in subsistence activities (Babulo et al. 2008). Households in Masha area for instance are engaged more in honey collection than bamboo, as honey from this part of the country entered into local market niches, since some time ago. It is also important to note that the current low income contribution of bamboo could also be due to the fact that subsistence income is not included in the income accountings. In contrast to the current findings, various studies in Ethiopia that took into account both subsistence and cash income (e.g., Mamo et al. 2007, Tesfaye et al. 2011) reported relatively higher amounts of forest-based incomes. For instance, Babulo et al. (2008) reported up to $69 \%$ contribution of forest income to a household's annual economy in northern rural Ethiopia. Similarly, Asfaw et al. (2013) based on their study in Jelo forest, eastern Ethiopia, found the annual contribution of forests to be $33 \%$ and the second largest in the household annual income.
Despite the modern use of bamboo in the rest of the world, such as China and India, bamboo utilization in the study areas is basically rudimentary. Hence, the significant potential of bamboo resources to the rural livelihoods and national economy is unrealized. Among the major bamboo use types identified at rural bamboo-growing areas and nearby towns were selling bamboo culms and only little value addition, such as processing bamboo in the form of tables, chairs, beds, etc. Despite the very weak links between them, the value chain assessment results show that fairly diverse actors including producer farmers, village level traders, town and city wholesalers, small- and medium-scale bamboo processing and marketing firms, and town and city consumers are involved as major actors in the bamboo value chain. The bamboo production-to-consumption value chain, however, is challenged due to lack of knowledge and skill, and differentiated markets suitable for different bamboo products, such as raw, processed, and semi-processed products. For instance, some $88 \%$ of respondents mentioned difficulties getting their bamboo products to markets, aside from the roadside markets, which are not persistent. Some key informants also mentioned presence of alternative tree and shrub species as factors hindering bamboo easily entering the existing market.

In conclusion, dependence on income from bamboo showed a wide range of variation from locality to locality and was affected by various household level socio-economic and exogenous factors, such as access to market and knowledge. The overall value chain assessment showed that bamboo products in Ethiopia had a very weak vertical and horizontal integration except some advancement around cities by small-scale bamboo-based firms and medium-scale enterprises that have started chain upgrading. Despite the inefficient value chains, respondents indicated an increasing trend of demand for bamboo products. Broad policy and development intervention measures are, therefore, needed to address the various challenges and constraints undermining the socio-economic and ecological importance of bamboo resources and to tap opportunities attached to the resources. It is apparent to develop a comprehensive strategy that will encompass sustainable bamboo resource management and utilization, organizing farmer-based cooperatives and bamboo entrepreneurship that will use the resources in innovative manners, improving the infrastructure that will add value to bamboo products and that can help to upgrade the value chain. The study shows that though few initiatives of bamboo domestication exist, the extension should engage in helping farmers develop their own small woodlots. In addition, during the field data collection, it was observed that the natural resource base is declining and bamboo stands in some areas are exposed to wide scale deforestation and fire. It is, hence, mandatory to protect and wisely manage the remaining forests. Farmers also mentioned their worries on the lack of efficient knowledge and skill to establish bamboo woodlots and 
how to manage them once established, which requires building capacity of the stakeholders, mainly at the bottom stage of the chain, such as via farmer training. Research has to come up with various innovative bamboo uses and management technologies, which currently do not seem to exist, except very few at the upper value chain. Technologies that diversify bamboo products based on consumer needs and behavior are crucial. Specific bamboo propagation and stand management techniques should be developed and communicated to the farmers. Further socio-economic research that comprehends the full value of bamboo resources to local, regional, and national economies and investigates how to improve the current low bamboo contribution to livelihoods is needed.

\section{Acknowledgments}

We thank Forestry Research Center (FRC) of the Ethiopian Institute of Agricultural Research (EIAR) for providing funding to undertake this research. We are greatly indebted to all the stakeholders at all levels in the value chains of bamboo, including farmers, experts, firms, and enterprise owners for their unreserved cooperation and data provision during the survey time. We extend our thanks to Alemayehu Negassa, Asamamaw Alemu, Kaleb Kelemu, and Birhane Kidane for their valuable contribution during inception of the research project, and Kassahun Mammo, Zebene Taddese, and Etenesh Mulu for their contribution during the field survey. We thank Worku Zewdie for preparing the study location map. Our sincere thanks also go to the two anonymous reviewers for their valuable contribution to improve the quality of an earlier version of the manuscript.

\section{Literature Cited}

Adnew, B. \& J. Statz. 2007. Bamboo Market Study in Ethiopia. Technical report prepared for UNIDO (United Nations Industrial Development Organization). Addis Ababa, Ethiopia.

Alito, M. 2005. Bamboo Reinforcement as Structural Material for the Construction of Low-Cost Houses in Ethiopia. MS Thesis, Addis Ababa University, Addis Ababa, Ethiopia.

Andargatchew, A. 2008. Value Chain Analysis for Bamboo Originating from Shedem Kebele, Bale Zone. MBA Thesis, Addis Ababa University, Addis Ababa, Ethiopia.

Asfaw, A., M. Lemenih, H. Kassa \& Z. Ewnetu. 2013. Importance, determinants and gender dimensions of forest income in eastern highlands of Ethiopia: The case of communities around Jelo Afromontane forest. Forest Policy and Economics 28:1-7. dx.doi.org/10.1016/j.forpol.2013.01.005
Babulo, B., B. Muys, F. Nega, E. Tollens, J. Nyssen, J. Deckers \& E. Mathijs. 2008. Household livelihood strategies and forest dependence in the highlands of Tigray, Northern Ethiopia. Agricultural Systems 98(2):147-155. http://hdl.handle.net/1854/LU-436312

Barrett, C.B., T. Reardon \& P. Webb. 2001. Nonfarm income diversification and household livelihood strategies in rural Africa: Concepts, dynamics, and policy implications. Food Policy 26(4):315-331.

Bay, A.V. 2004. Bamboo (Neohouzeaua dullooa) production and trade in Cho Don, Vietnam: NTFP extraction from allocated forest lands. Pp 335-346 in Forest Products, Livelihoods and Conservation: Case studies of Non-timber Forest Product systems, Volume 1- Asia. Edited by K. Kusters \& B. Belcher. Center for International Forestry Research (CIFOR), Bogor, West Java, Indonesia. www. cifor.org/ntfpcd/pdf/ntfp-asia-r.pdf

Belcher, B., M. Ruiz-Pérez \& R. Achdiawan. 2005. Global patterns and trends in the use and management of commercial NTFPs: Implications for livelihoods and conservation. World Development 33(9):1435-1452. dx.doi. org/10.1016/j.worlddev.2004.10.007

Bewketu, Z. 2009. Bamboo: An alternative building material for urban Ethiopia. MS Thesis, California Polytechnic State University, San Luis Obispo, California, U.S.A.

Campbell, B.M, S. Jeffrey, W. Kozanayi, M. Luckert, M. Mutamba \& C. Zindi. 2002. Household Livelihoods in Semi-Arid Regions: Options and constraints. Center for International Forestry Research (CIFOR), Bogor, West Java, Indonesia. www.cifor.org/publications/pdf files/ books/household.pdf

Carr, M. \& M. Hartl. 2008. Gender and Non-Timber Forest Products: Promoting food security and economic empowerment. IFAD (International Fund for Agricultural Development), Rome, Italy. www.ifad.org/gender/pub/timber.pdf Accessed 15 April 2011.

Creswell, J.W. 2009. Research Design: Qualitative, quantitative and mixed methods approaches. Third edition. SAGE Publications, New Delhi, India.

DFID (Department for International Development). 1999. Sustainable Livelihood Guidance Sheets. DFID, London, U.K.

Ellis, F., M. Kutengule \& A. Nyasulu. 2003. Livelihoods and rural poverty reduction in Malawi. World Development 31(9):1495-1510. $\mathrm{dx} . \mathrm{doi} . \mathrm{org} / 10.1016 / \mathrm{S} 0305-$ 750X(03)00111-6

Embaye, K. 2000. The indigenous bamboo forests of Ethiopia: An overview. AMBIO: A journal of the human envi- 


\section{Mekonnen et al. - Bamboo Resources in Ethiopia: Their value chain and 523 contribution to livelihoods}

ronment 29(8):518-521. dx.doi.org/10.1579/0044-7447$\underline{29.8 .518}$

Embaye, K. 2003. Ecological Aspects and Resource Management of Bamboo Forests in Ethiopia. Doctoral dissertation, Swedish University of Agrocultural Science (SLU), Uppsala, Sweden.

Embaye, K., L. Christersson, S. Ledin \& M. Weih. 2003. Bamboo as bioresource in Ethiopia: Management strategy to improve seedling performance (Oxytenanthera abyssinica). Bioresource Technology 88(1):33-39. dx.doi. org/10.1016/S0960-8524(02)00265-1

FAO (Food and Agriculture Organization of the United Nations). 2003. Bamboo and Rattan Statistics Expert Consultation on Developing an Action Programme Towards Improved Bamboo and Rattan Trade Statistics. Meeting proceedings, Rome, Italy, 5-6 December 2002. FAO, Rome, Italy. www.fao.org/docrep/019/y4782e/y4782e.pdf

FAO (Food and Agriculture Organization of the United Nations). 2006. Global Forest Resources Assessment Updates 2005: Country report on bamboo resources (final draft): Addis Ababa, Ethiopia. Working Paper 117. FAO, Rome, Italy, and INBAR (International Network for Bamboo and Rattan), Beijing, China.

Gebremariam, A.H., M. Bekele \& A. Ridgewell. 2009. Small and Medium Forest Enterprises in Ethiopia. IIED Small and Medium Forest Enterprise Series No. 26. FARM-Africa and International Institute for Environment and Development, London, U.K. http://pubs.iied.org/ pdfs/13553IIED.pdf

Haile, B. 2008. Study on Establishment of Bamboo Processing Plants in Amhara Regional State. MS Thesis, Addis Ababa University, Addis Ababa, Ethiopia.

Hedberg I. \& S. Edwards, eds. 1995. Flora of Ethiopia and Eritrea. Poaceae. Volume 7. The National Herbarium, Addis Ababa, Ethiopia, and Uppsala University, Uppsala, Sweden.

INBAR (International Network for Bamboo and Rattan). 2010. Study on Utilization of Lowland Bamboo in Benishangul Gumuz Region, Ethiopia. Beijing, China. www.inbar.int

ITTO (International Tropical Timber Organization). 2002. Tropical Timber Products: Development of further processing in ITTO producer countries. International Trade Centre (ITC), Geneva, Switzerland, and ITTO, Yokohama, Japan.

Kamanga, P., P. Vedeld \& E. Sjaastad. 2009. Forest income and rural livelihoods in Chiaduzulu District, Ma- lawi. Ecological Economics 68(3):613-624. dx.doi. org/10.1016/j.ecolecon.2008.08.018

Kant, S. 1996. Integration of biodiversity conservation in tropical forest and economic development of local communities. Journal of Sustainable Forestry 4(1-2):33-61. dx.doi.org/10.1300/J091v04n01 02

Kar, S.P. \& M.G. Jacobson. 2012. NTFP income contribution to household economy and related socio-economic factors: Lessons from Bangladesh. Forest Policy and Economics 14(1):136-142. dx.doi.org/10.1016/j.forpol.2011.08.003

Kelbessa, E., T. Bekele, A. Gebrehiwot \& G. Hadera. 2000. A Socio-Economic Case Study of the Bamboo Sector in Ethiopia: An analysis of the production-to-consumption system. Addis Ababa University, Addis Ababa, Ethiopia.

Kelemework, S. 2008. Testing of Two Ethiopian Bamboo Species for Value Add Products. Forestry Research Center, Addis Ababa, Ethiopia.

Kibwage, J.K. \& S.E. Misreave. 2011. The Value Chain Development and Sustainability of Bamboo Housing in Ethiopia. International Network for Bamboo and Rattan, Beijing, China.

Kibwage, J.K., A.J. Odondo \& G.M. Momanyi. 2008. Structure and performance of formal retail market for bamboo products in Kenya. Scientific Research and Essays 3(6):229-239.

Lee, A.W.C. \& Y. Liu. 2003. Selected physical properties of commercial bamboo flooring. Forest Products Journal 53(6):23-26.

Mamo, G., E. Sjaastad \& P. Vedeld. 2007. Economic dependence on forest resources: A case from Dendi District, Ethiopia. Forest Policy and Economics 9(8):916-927. dx.doi.org/10.1016/j.forpol.2006.08.001

Man, N. \& S.I. Sadiya. 2009. Off-farm employment participation among paddy farmers in the Muda Agricultural Development Authority and Kemasin Semerak granary areas of Malaysia. Asia-Pacific Development Journal 16(2):141-153.

Maoyi, F. \& A.V. Bay. 2004. Bamboo: Green and gold in China and Vietnam. Pp. 45-50 in Riches of the Forest: Food, spices, crafts and resins of Asia. Edited by C. López \& P. Shanley. Center for International Forestry Research (CIFOR), Bogor, West Java, Indonesia.

Marshall, E., K. Schreckenberg \& A.C. Newton, eds. 2006. Commercialization of Non-Timber Forest Products: Factors influencing success. Lessons learned from Mexico 
and Bolivia and policy implications for decision-makers. United Nations Environment Programme, World Conservation Monitoring Centre, Cambridge, U.K.

Nugroho, N. \& A. Naoto. 2001. Development of structural composite products made from bamboo II: Fundamental properties of laminated bamboo lumber. Journal of Wood Science 47(3):237-242. dx.doi.org/10.1007/BF01171228

Ogunjinmi, A.A., H.M. ljeomah \& A.A. Aiyeloja. 2009. Socio-economic importance of bamboo (Bambusa vulgaris) in Borgu local government area of Niger State, Nigeria. Journal of Sustainable Development in Africa 10(4):284298.

Ohrnberger, D. 1999. The Bamboos of the World: Annotated nomenclature and literature of the species and the higher and lower taxa. Elsevier Science, Amsterdam, Netherlands.

Rana, M.P., S.A. Mukul, M.S.I. Sohel, M.S.H. Chowdhury, S. Akhter, M.Q. Chowdhury \& M. Koike. 2010. Economics and employment generation of bamboo-based enterprises: A case study from eastern Bangladesh. Small-Scale Forestry 9(1):41-51. dx.doi.org/10.1007/s11842-009$\underline{9100-8}$

Sertse, D., T. Disasa, K. Bekele, M. Alebachew, Y. Kebede, N. Eshete \& S. Eshetu. 2011. Mass flowering and death of bamboo: A potential threat to biodiversity and livelihoods in Ethiopia. Journal of Biodiversity and Environmental Sciences 1(5):16-25.

Tesfaye, Y., A. Roos, B.M. Campbell \& F. Bohlin. 2011. Livelihood strategies and the role of forest income in participatory-managed forests of Dodola area in the bale highlands, southern Ethiopia. Forest Policy and Economics 13(4):258-265. dx.doi.org/10.1016/j.forpol.2011.01.002

Vedeld, P., A. Angelsen, J. Bojø, E. Sjaastad \& G.K. Berg. 2007. Forest environmental incomes and the rural poor. Forest Policy and Economics 9(7):869-879. dx.doi. org/10.1016/j.forpol.2006.05.008
Vedeld, P., A. Angelsen, E. Sjaastad \& G.K. Berg. 2004. Counting on the Environment: Forest incomes and the rural poor. Environmental Economics Series. Paper No. 98. The World Bank Environment Department, Washington, D.C., U.S.A.

Wang, X. 2006. Comparative Analysis and Policy Recommendations on Developing Bamboo Resource Tenure Systems in Asia and Africa. Joint Project in Cooperation with International Network for Bamboo and Rattan, Beijing, China, and World Forest Institute, Portland, Oregon, U.S.A.

Worku, A., M. Lemenih, M. Fetene \& D. Teketay. 2011. Socio-economic importance of gum and resin resources in the dry woodlands of Borana, southern Ethiopia. Forest, Trees and Livelihoods 20(2-3):137-156. dx.doi.org/1 $\underline{0.1080 / 14728028.2011 .9756703}$

Yemishaw, Y., D. Teketay, A. Worku \& Y. Yohannes. 2009. Gathering storm: The fate of forestry research and development in Ethiopia. Pp. 11-38 in Proceedings of Forestry at Cross Road in Ethiopia: The way forward. Edited by Nigusu Aklilu. Hilton Hotel, 21-23 March, Addis Ababa, Ethiopia.

Yin, R.K. 2009. Case Study Research: Design and methods. Fourth Edition. Applied Social Research Methods Series, Volume 5. SAGE Publications, New Delhi, India.

Yiping, L., L. Yanxia, K. Buckingham, G. Henley \& Z. Guomo. 2010. Bamboo and Climate Change Mitigation: A comparative analysis of carbon sequestration. International Network for Bamboo and Rattan Technical Report No. 32. Beijing, China.

Zhaohua, Z., ed. 2001. Sustainable Development of the Bamboo and Rattan Sectors in Tropical China. Proceedings No. 6. International Network for Bamboo and Rattan (INBAR), Beijing, China.

Zhaohua, Z. \& E. Yang. 2004. Impact of Assessment of Bamboo Shoot on Poverty Reduction in Lin'an, China. Working Paper No. 52. International Network for Bamboo and Rattan (INBAR), Beijing, China. 